\title{
THERMAL CRACKING OF LARGE-DIAMETER 706 INGOTS
}

\author{
Ramesh S. Minisandram, Laurence A. Jackman, Charles B. Adasczik, Rajiv Shivpuri* \\ Allvac (An Allegheny Teledyne Company), Monroe, NC \\ *Ohio State University, Columbus, $\mathrm{OH}$
}

\begin{abstract}
Large circumferential cracks were revealed when two alloy 706 ingots $865 \mathrm{~mm}$ in diameter were cropped at the bottom end following homogenization. Both ingots were part of a program evaluating a modified start-up practice for VAR. Since they were the only ingots with the modified practice and the only ingots exhibiting this cracking behavior, the modified practice was identified as the cause of this problem. It appears that residual stresses generated during the modified VAR start-up and thermal stresses created during heat up for homogenization combined to initiate cracking during heat up. In order to explore this mechanism, numerical simulations were applied. Although stresses generated during VAR start-up could not be calculated because of complicated transient effects, thermal stresses generated during heating for homogenization were calculated to be sufficiently large to support this mechanism. Also, crack location matched well with the location of maximum principal stress during the early stage of heat up for homogenization. Cracking propagated intergranularly and was located in the nearly equiaxed coarse grain outer region near the transition to a columnar grain structure.
\end{abstract}

Superalloys $718,625,706$ and Various Derivatives

Edited by E.A. Loria

The Minerals, Metals \& Materials Society, 1997 


\section{Introduction}

Alloy 706 was developed in response to the nced for an alloy that could be melted to large cross sections without segregation problems $(1,2)$. Since the late 1980 's, large diameter 706 ingots have been used for heavy duty industrial gas turbine wheels. One concern with these large sizes is the thermal stresses that build up during various stages of processing. This has not been a problem because standard practices have been develuped which preclude the formation of thermal stresses sufficiently large to initiate cracks. However, deviations from standard practice can result in cracking from thermal stresses. This became evident when a modified start-up practice for VAR (Vacuum Arc Remelting) was evaluated for two ingots $864 \mathrm{~mm}$ in diameter. Both ingots revealed a large circumferential crack when the bottom end was cleared after homogenization. In an effort to achieve better understanding and to help evaluate potential process improvements, numerical modeling was applied to this situation. Numerical solutions have been applied to heat transfer/thermal stress problems for a number of years. Among the earliest attempts was that by Sun (3) which described how the heating practice for a 40 " Hastelloy $\mathrm{X}^{\circledR}$ ingot may be optimized. The work by Suarez et al (4) considered melting and solidification of 706 ingots and showed, through a combination of numerical analysis and closed form solutions, that the residual stresses at the end of cooling after melt and those due to subsequent reheating are additive. Chandrasekharan $\&$ Shivpuri (5) used numerical techniques to optimize heating schedules for nickel based superalloys. Alam \& Semiatin (6) calculated residual stresses in VAR melted gamma titanium aluminide ingots. Their conclusion was that residual radial stresses are mostly tensile in the lower portion of the ingot and mostly compressive in the upper portion.

\section{Characterization of Material}

The two ingots that exhibited cracking were similar with regard to crack appearance and location. Therefore, only one ingot was characterized; all material information provided in the report will represent this one ingot. It was triple melted by VIM (Vacuum Induction Melting) + ESR (Electro-Slag Remelting) + VAR. Chemistry was normal, as shown in Table I.

Table I - Chemistry of Alloy 706 Ingot that Exhibited Thermal Crack

\begin{tabular}{|c|c|c|c|c|c|c|c|c|c|c|}
\hline Element & C & Mri & Si & Cr & Ni & Fe & Ti & Al & Mo & Nb+ta \\
\hline Wt. $\%$ & 0.015 & 0.04 & 0.07 & 15.90 & 41.90 & 36.78 & 1.67 & 0.18 & 0.21 & 3.00 \\
\hline
\end{tabular}

The ingot was then homogenized followed by an overaging treatment to facilitate cutting, and conditioned by grinding; at this stage of the processing, no cracking of the ingot was evident. However, a large circumferential crack was revealed when a crop about $64 \mathrm{~mm}$ long was taken from the bottom end of the ingot. The crack was still present after additional crops of $165 \mathrm{~mm}$ and $50 \mathrm{~mm}$ were taken; it was cleared by a final crop of $267 \mathrm{~mm}$. Ingot cutting at the bottom end is illustrated schematically in Figure 1. The crack is shown in the macrograph in Figure 2 which represents the bottom end of the $267 \mathrm{~mm}$ mult shown in Figure 1 ; this surface is about $280 \mathrm{~mm}$ from the bottom of the ingot. Bleeding of the etchant out of the crack in Figure 2 caused the crack to appear thicker than the actual separation. Where the bleeding of the etch was severe, the maximum separation approached $1 \mathrm{~mm}$; there was little separation towards the end of the crack. The region from about 9 to 11 o'clock in Figure 2 did not crack, probably because residual stresses were significantly reduced by the separation that took place when cracking occurred. 


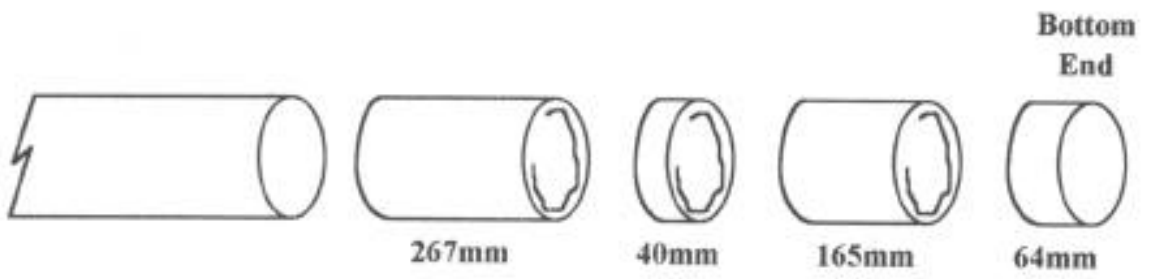

Figure 1. Cutting Diagram of Cracked Alloy 706 Ingot $864 \mathrm{~mm}$ in Diameter

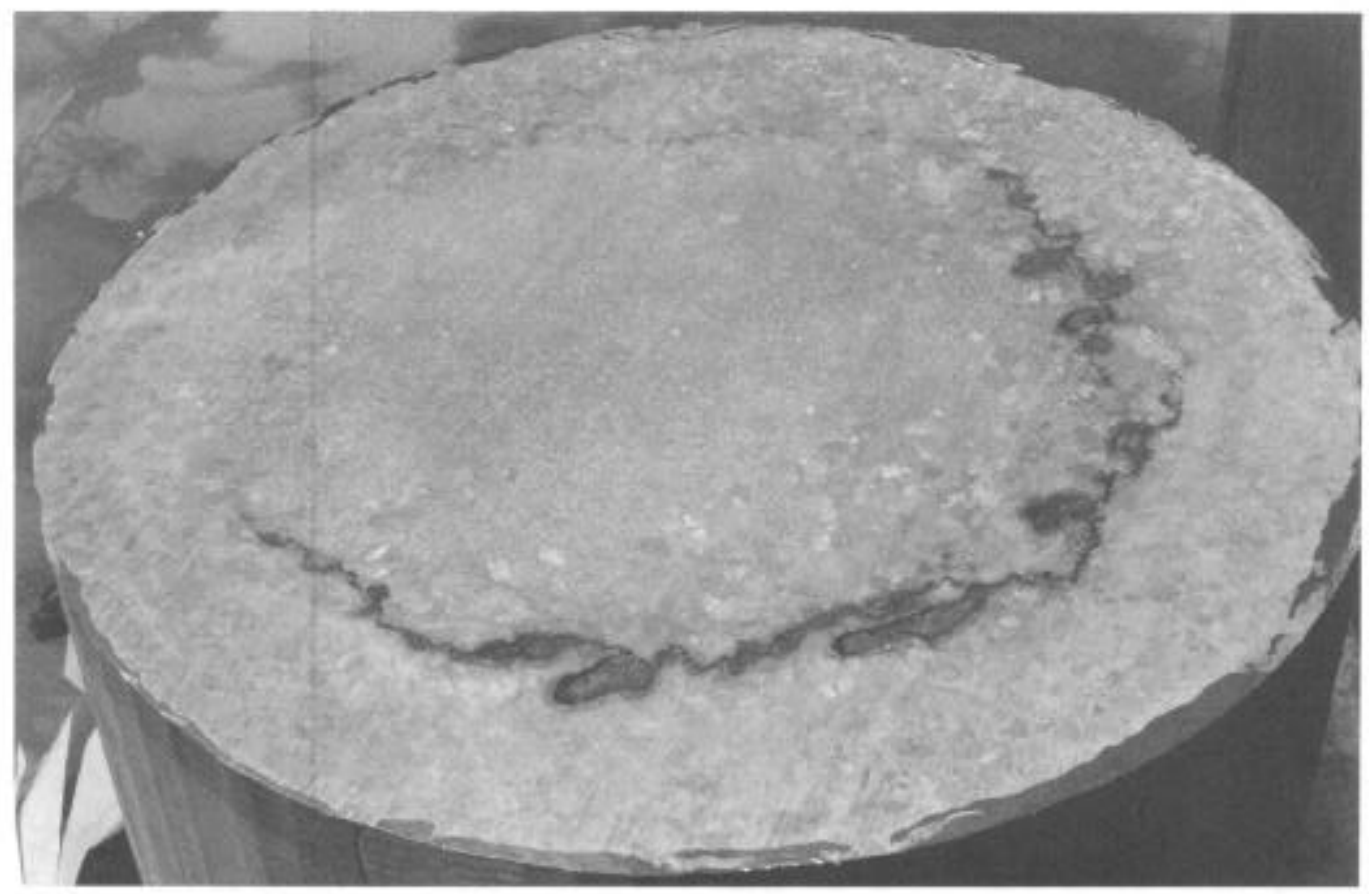

Figure 2. Etched Surface Showing Crack in Alloy $706 \mathrm{Ingot} 864 \mathrm{~mm}$ in Diameter. Surface is About $280 \mathrm{~mm}$ from the Bottom of the Ingot. It is the Bottom End of the $267 \mathrm{~mm}$ Mult Shown in Figure 1 . Ingot has been Conditioned to About $813 \mathrm{~mm}$ in Diameter.

Figure 2 also reveals that the circumferential crack is close to the transition from large and somewhat equiaxed grains in the surface region to thinner columnar grains in the interior region. This is further illustrated in Figure 3 which shows sections of the $40 \mathrm{~mm}$ thick macro slice; locations of these sections are indicated in Figure 3a. The longitudinal view in Figure $3 \mathrm{~d}$ readily shows the transition to columnar grains. The intergranular nature of the crack is visible in Figures $3 \mathrm{~b}$ and $3 \mathrm{c}$. Blanks $128 \mathrm{~mm}$ diameter for tensile specimens were also cut from the $40 \mathrm{~mm}$ macro slice. As indicated in Figure 3e, these tensile blanks were cut from both the surface region with large grains and the interior region with an equiaxed grain structure. Results from tensile testing are presented in Table II where each result represents an average of at least two tests. The strength and ductility are lower in the surface region, which is not surprising in view of the larger grain size in this region.

Specimens for microstructural evaluation were also taken from the $40 \mathrm{~mm}$ macro slice both at the crack location and away from the crack. No unusual microstructural features were observed. The intergranular nature of the crack path was readily evident in these specimens. 

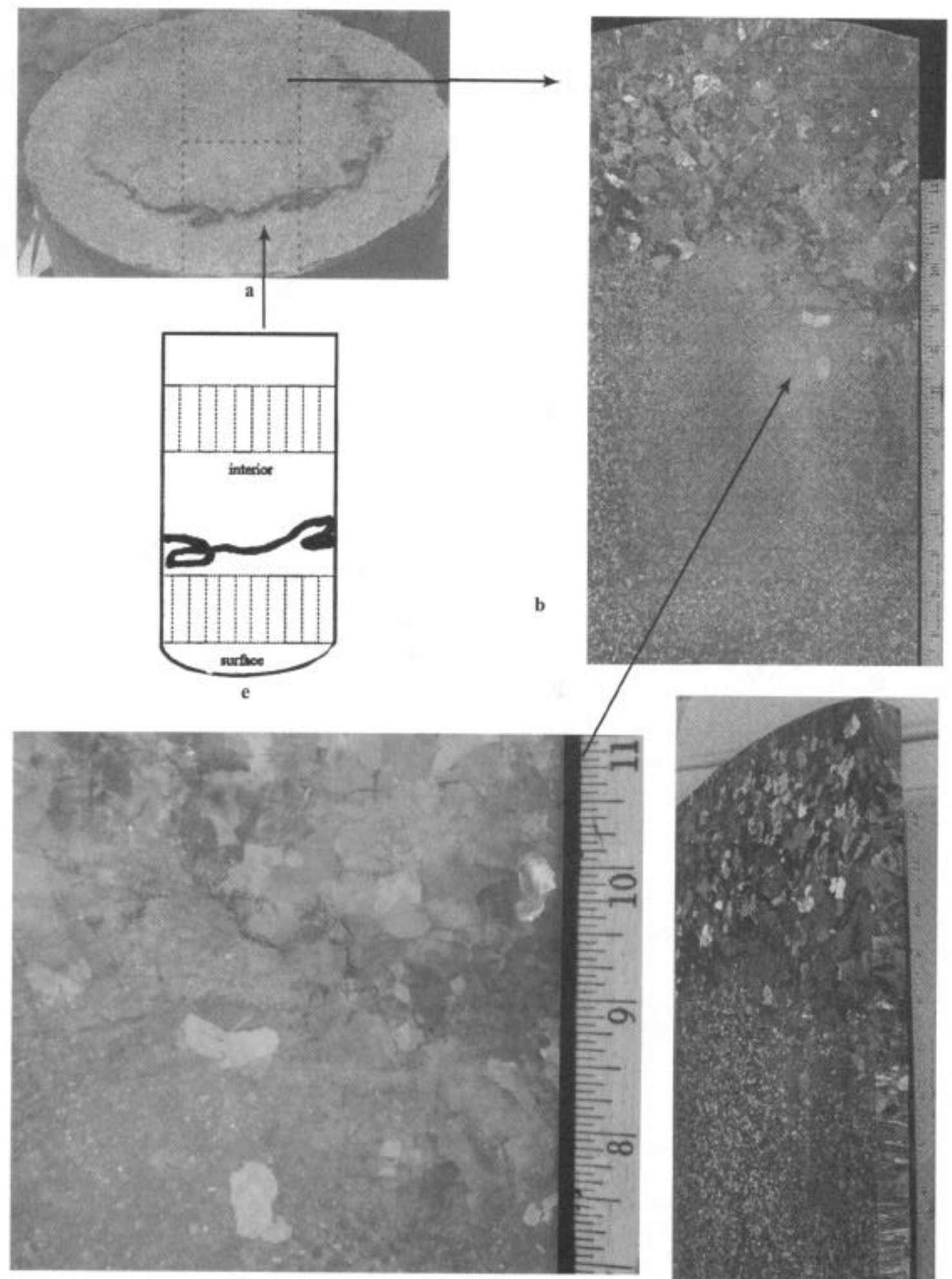

c

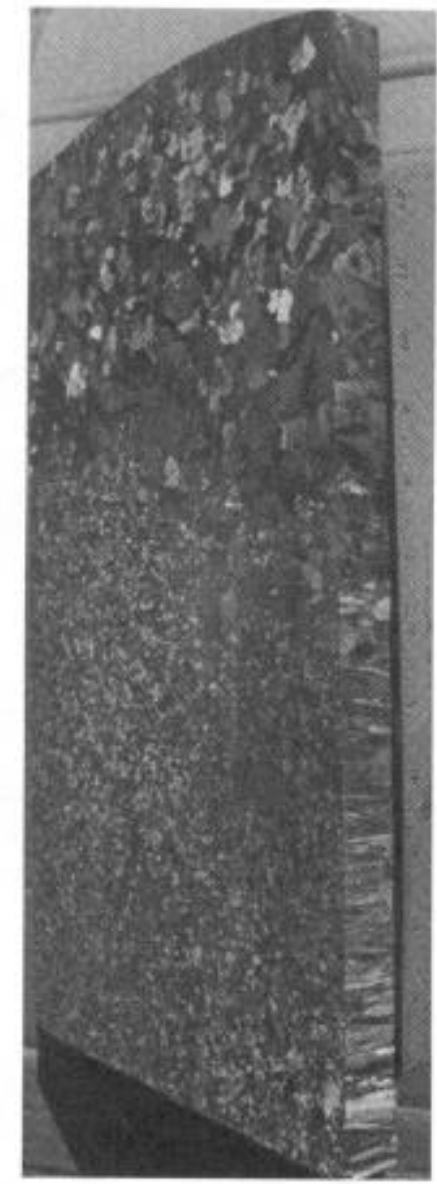

Figure 3. Crack in Alloy 706 Ingot Slices. (a) Cutting Diagram for Macro Slices, (b) Macro Slice Showing Grain Structure, (c) Enlarged View of Macrostructure at Crack, (d) Macro Slice in b Oriented to Show Longitudinal Direction, and (e) Cutting Diagram for Tensile Specimens, 
Table II. Tensile Properties at Various Temperatures for Surface and Interior Locations of the Cracked Alloy 706 Ingot

\begin{tabular}{|c|c|c|c|c|c|}
\hline \multirow{2}{*}{$\begin{array}{c}\text { TEMPERATURE } \\
\left({ }^{\circ} \mathbf{C}\right)\end{array}$} & \multirow{2}{*}{ LOCATION } & YS & UTS & & \\
\cline { 3 - 6 } & Mpa & Mpa & \% EL & \% RA \\
\hline 20 & Surface & 313.7 & 470.9 & 6.5 & 12.1 \\
\hline 20 & Interior & 434.4 & 660.5 & 9.0 & 14.8 \\
\hline 650 & Surface & 241.3 & 462.0 & 10.0 & 16.9 \\
\hline 650 & Interior & 388.2 & 579.2 & 10.8 & 20.3 \\
\hline 815 & Interior & 255.1 & 335.8 & 29.2 & 57.5 \\
\hline 982 & Interior & 51.2 & 72.3 & 92.3 & 97.3 \\
\hline
\end{tabular}

\section{Proposed Mechanism}

A modified VAR start-up practice was used on the two ingots that experienced bottom end cracking; this modified practice was not used on any other ingots. Since cracking does not occur with standard processing, it can be concluded that the modified VAR start-up practice was responsible for the cracking. The most plausible scenario is that residual stresses generated by the modified VAR start-up practice were larger than the thermal stresses associated with the standard practice. While they were probably not sufficient to cause cracking at that processing step, they were additive to thermal stresses generated during heat up for homogenization. It is proposed that cracking occurred during heating for homogenization due to the combination of thermal stresses from the modified VAR practice and from the heat up practice used for homogenization.

Higher thermal stresses were generated by the modified VAR start-up practice relative to standard processing because the initial melt rate peaked to a higher level. The modified practice is illustrated in Figure 4 which provides melt rate versus time for the start-up region of the cracked ingot. It peaks about $25 \%$ above the standard practice. The melt rates in Figure 4 are averages of 20 minute intervals.

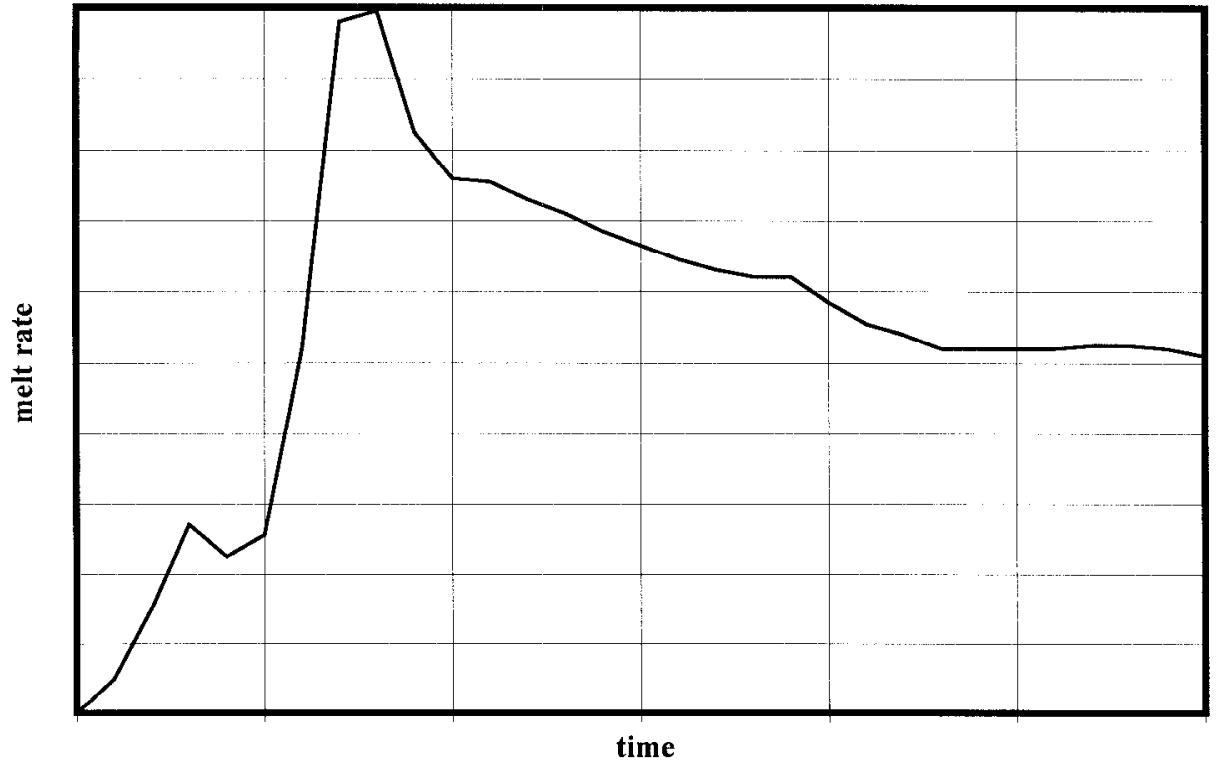

Figure 4. Melt Rate Profile for Modified Start-Up Practice. Melt Rates are 20 Minute Averages. 
The direct approach towards substantiating the cause of cracking would be to determine residual stresses from the modified VAR practice and add them to stresses calculated for the heat up for homogenization. If the sum is in a danger region, cracking would be predicted. A model for calculating temperature profiles, and therefore stresses during VAR has been developed through SMPC (Specialty Metals Processing Consortium). However, it cannot provide detailed temperature profiles in the ingot for the complicated transient stage of start-up. The complexity of the start-up stage is evident from the nonsymmetric grain structural patterns often observed in bottom crops cut from standard processed ingots. This nonsymmetry is also apparent in Figure 2. Consequently, the approach pursued was to determine thermal stresses generated during heat up for homogenization at the location of the crack. The magnitude and distribution of these stresses can be evaluated to determine if the proposed mechanism is plausible.

\section{Analysis of Heat Up for Homogenization}

\section{Finite Element Model}

Heating of the Alloy 706 ingot was modeled using the ABAQUS finite element software (version 5.5-1). The ingot was assumed to be an axisymmetric body with a symmetry plane at mid-height. These assumptions enabled a $2 \mathrm{D}$ model to be used with quarter geometry being simulated. A fine mesh comprising 1617 nodes and 1520 elements was used. The ingot geometry and boundary conditions are shown in Figure 5. The planes identified in Figure 5 represent locations for which results will be presented.

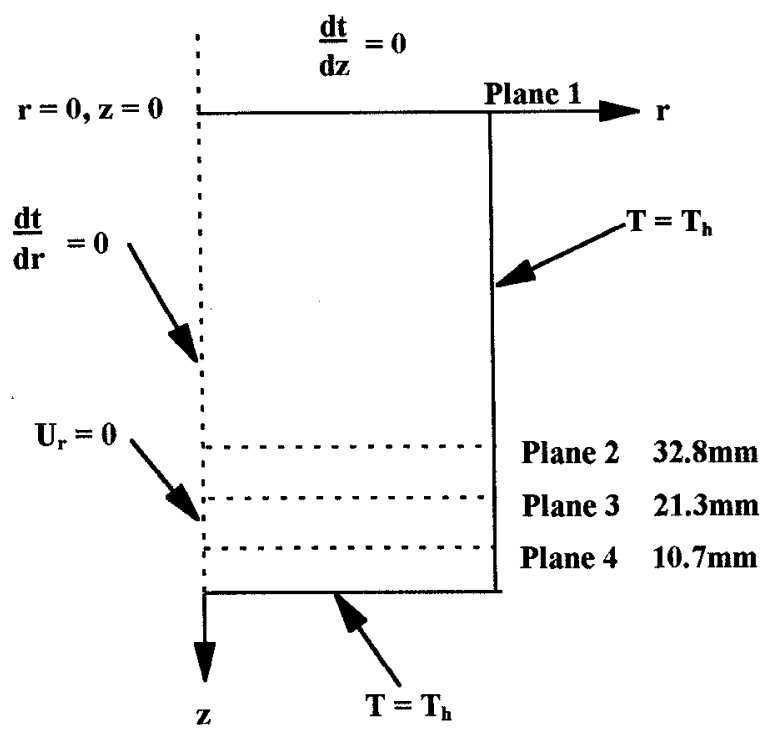

Figure 5. Domain for Finite Element Calculations

Boundary Conditions were as follows:

- The nodes on the axis are constrained in the radial direction $\left(\mathrm{U}_{\mathrm{r}}=0\right)$.

- No radial heat flux at the axis $(\mathrm{dT} / \mathrm{dr}=0)$.

- The nodes on the plane $\mathrm{z}=0$ (plane of symmetry) are constrained in the axial direction $\left(\mathrm{U}_{z}=0\right)$.

- No axial heat flux at the planc $\mathrm{z}=0,\left(\mathrm{dT} / \mathrm{dz}==^{2} 0\right)$.

- Convective and radiative heat transfer at the outer surfaces. 
An elastic material model was assumed with the material properties taken as a function of temperature only. Properties were available in the literature up to $700^{\circ} \mathrm{C}$; extrapolation was used for higher temperatures. Although emissivity can be a function of temperature and ingot placement in the furnace, it was assumed to have a fixed value.

\section{Simulation Results}

The heat up for homogenization consisted of charging the ingot into a furnace at $760^{\circ} \mathrm{C}$ and holding for a long period of time prior to ramping up at a controlled rate to the homogenization temperature. This process was simulated on ABAQUS as described above and pertinent results are presented in Figures 6,7, and 8. In these figures, a distance of 0 corresponds to the ingot axis and a value of one to the ingot surface. As expected, the maximum thermal gradients in the ingot occur early in the heat up process. This is shown in Figure 6, where the surface-to-center temperature variation for the central plane (plane $1, \mathrm{z}=0$ ) is presented at various times.

The stress levels in the ingot have been represented in terms of the maximum principal stresses. This quantity is used because of the low ductility and large grains associated with the as-cast ingot structure. Contour plots of temperatures and stresses wcre generated to provide an overview. These indicated the maximum stress levels in the mid-radius region occur early on in the process ( 2875 seconds) and that they occur at a distance of about $21 \mathrm{~mm}$ from the ingot end. Plane 3 was selected to coincide with this location. Figures 7 and 8 represent, respectively, the radial variation of temperature and stress in the ingot at this time ( 2875 seconds) at planes $1,2,3$, and 4 . Stresses peak on plane 3 around $200 \mathrm{~mm}$ but the peak is relatively broad. The actual crack was located between $114 \mathrm{~mm}$ and $165 \mathrm{~mm}$. This is considered good agreement in view of the fact that the peak stress is probably displaced somewhat when residual stresses from start-up are added to these heat up stresses. Calculated stresses are slightly larger than anticipated, which may be related to the use of an elastic model that does not account for stress relaxation. At later times, the location of maximum stress is at the center of the ingot.

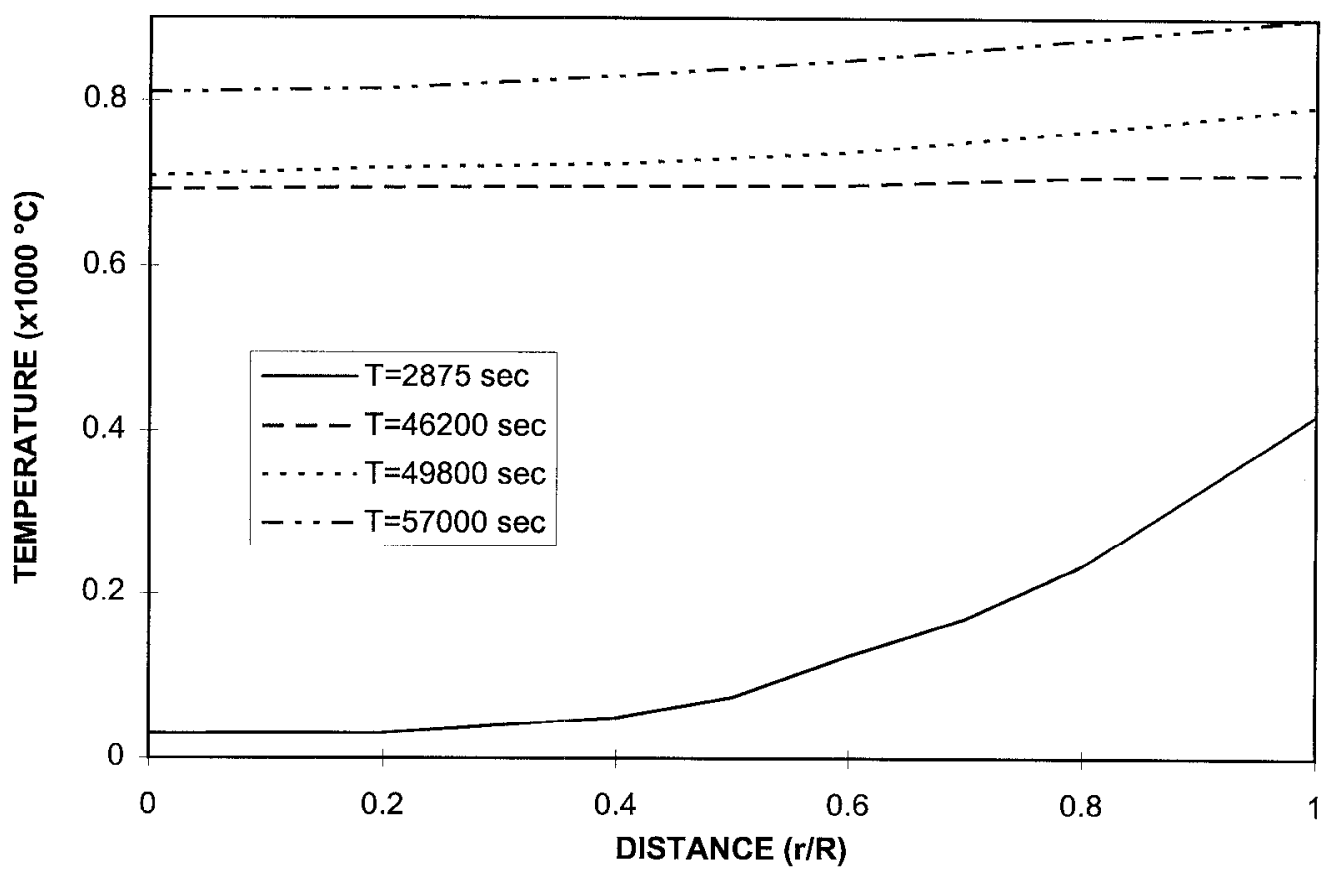

Figure 6. Radial Variation of Temperature at Central Plane $(z=0)$ at Different Times 137 


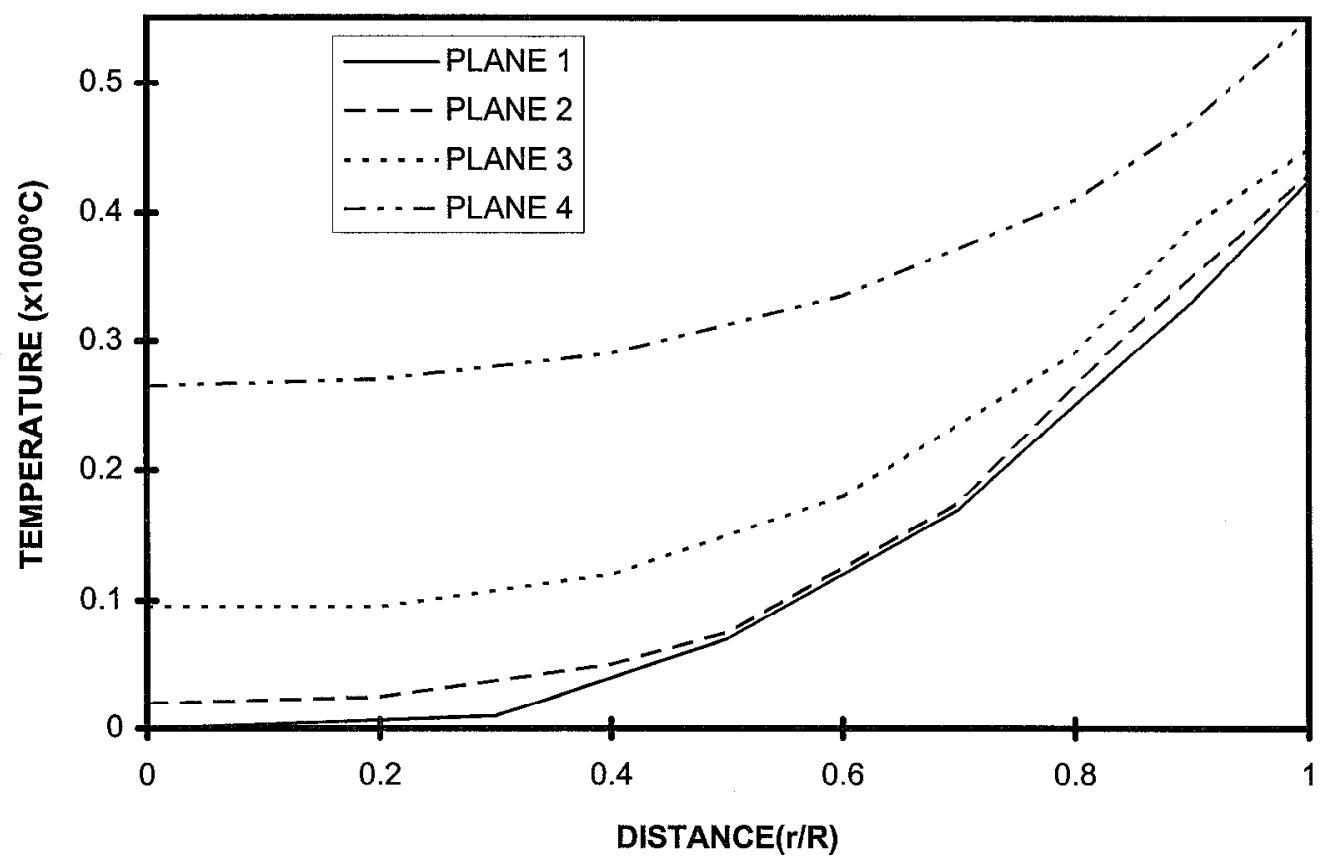

Figure 7. Temperature Distribution in Planes 1, 2, 3, and 4 at Time $=2875$ Seconds

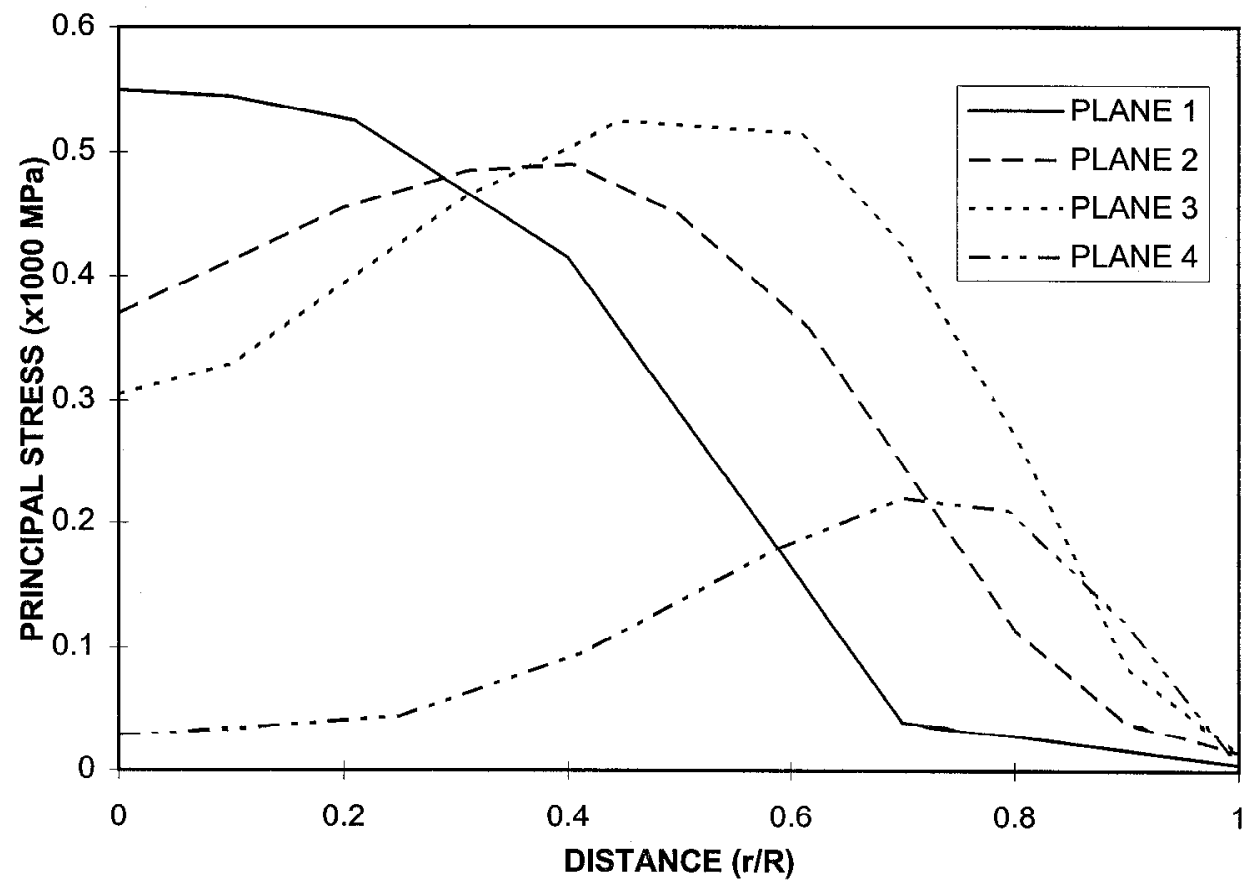

Figure 8. Stress Distribution in Planes 1, 2, 3, and 4 at Time $=2875$ Seconds 


\section{Conclusions}

- Circumferential cracking was observed in two alloy 706 ingots when the bottom ends were cropped following homogenization. This was attributed to a modified start-up practice in VAR that was used only for these two ingots.

- It is believed that cracking occurred during heat up for homogenization from the additive effect of residual stresses generated from the modified VAR start-up and thermal stresses developed during heating for homogenization.

- Stresses generated during VAR start-up could not be calculated because of complicated transient effects, but thermal stresses generated during heating for homogenization support this mechanism. Crack location matched well with the location of maximum principal stress during the early heat up for homogenization.

- Cracking occurred intergranularly in the nearly equiaxed coarse grain outer region; tensile testing revcaled this region to be weaker and less ductile than the interior region that had a columnar grain structure. The crack was close to the transition between predominantly equiaxed and columnar grains.

\section{Acknowledgments}

Thanks are due to Vikas Goel and Karthik Suryanarayanan for the computer simulations. Also, technical assistance was provided by Billy Hendrick and Jeff Russell.

\section{References}

1. P. W. Schilke, J. J. Pepe, R. C. Schwant, Alloy 706 Metallurgy and Turbine Wheel Application, Superalloys 718, 625,706 and Various Derivatives, ed. E. A. Loria (TMS, 1994), $1-12$.

2. A. D. Helms, C. B. Adasczik, L. A. Jackman, Extending the Size Limits of Cast/Wrought Superalloy Ingots, Superalloys 1996, (TMS, 1996), 427-43.

3. R. C. Sun, "Determination of the Forging-Heating Schedule for a Large "HASTELLOY" Alloy X Ingot," Metallurgical Transactions, 1, (7) (1970), 1881-1887.

4. F. S. Suarez, J. E. Roberts, and L. D. Schley, "Ingot -Size Optimization in a Superalloy -Inconel Alloy 706," Fifth International Symposium on Electroslag and Other Special Melting Technologies, (Carnegie-Mellon Institute of Research, Pittsburgh, PA, 1975), (1), 126-149.

5. M. K. Alam, and S. L. Semiatin, "Thermal Stress Development During Processing of Ingots," in Processing and Fabrication of Advanced Materials for High Temperature Applications-II, ed. V. A. Ravi, and T. S. Srivatsan, (The Minerals, Metals, and Materials Society, 1993), 593-607.

6. M. K. Alam, R. L. Goetz, and S. L. Semiatin, "Modeling of Thermal Stresses and Thermal Cracking during Heating of Large Ingots," Journal of Manufacturing Science and Engineering, 118, (2), (May 1996), 235-243.

7. S. Chandrasekharan and R. Shivpuri, "Optimization of Pre-Heating Schedules for Nickel Base Superalloy Ingots Using Finite Element Method," (Report ERC/NSM-B-92-09, NSF Engineering Research Center for Net Shape Manufacturing, The Ohio State University, Columbus OH, February, 1992). 